\title{
Agrocombustibles vs. Producción de Alimentos
}

\section{Manuel B. Suquilanda Valdivieso.}

Resumen - El estado ecuatoriano, ha venido en los últimos tiempos haciendo algunas consideraciones alrededor de la pertinencia de llevar adelante en el territorio nacional, la producción de cultivos destinados para la obtención de agrocombustibles.

Fundamentalmente se argumenta que las importaciones de combustibles significan un alto costo para el Estado, a lo que se suman la emisiones de gases en el ambiente por el uso de hidrocarburos.

Para dar cumplimiento a la política energética estatal en base al uso de combustibles menos contaminantes, se manifiesta que en el país existen recursos agrícolas que permiten la producción de biocombustibles. (Condiciones climáticas y ubicación favorable).

En muchos sectores del país, ya se viene promocionando con fuerza los cultivos que se dedicarán a la obtención de agrocombustibles y también ya se están ejecutando acciones, sin embargo no se ha analizado conjuntamente con los agricultores, su pertinencia frente a la producción de alimentos, que al escasear comprometerían seriamente la soberanía alimentaria de la sociedad ecuatoriana..

Palabras clave- Agrocombustibles, Agrotóxicos, Biocombustibles, Biodiesel, Bioenergía, Seguridad alimentaria.

\section{Introducción}

Mediante Decreto Ejecutivo No 2332, publicado en el Registro Oficial 482 del 15 de noviembre del 2004, el estado ecuatoriano, con el fin de promover el uso de los biocombustibles, declara de interés nacional a la producción, comercialización y uso de los biocombustibles, creando para dicho efecto el Consejo Consultivo de Biocombustibles, adscrito a la Presidencia de la República y presidido por el Ministro de Energía, haciendo parte de este Consejo también los gremios del sector privado del sector cañicultor.

El Programa de Biocombustibles, a su vez tiene entre sus propósitos los siguientes:

- Reducción de la contaminación ambiental y consumo de combustibles fósiles. para dar cumplimiento al compromiso de 1 Manuel B. Suquilanda Valdivieso MB. Universidad Tecnológica Equinoccial 098042005/2470317·m.suquilanda@andinanet.net

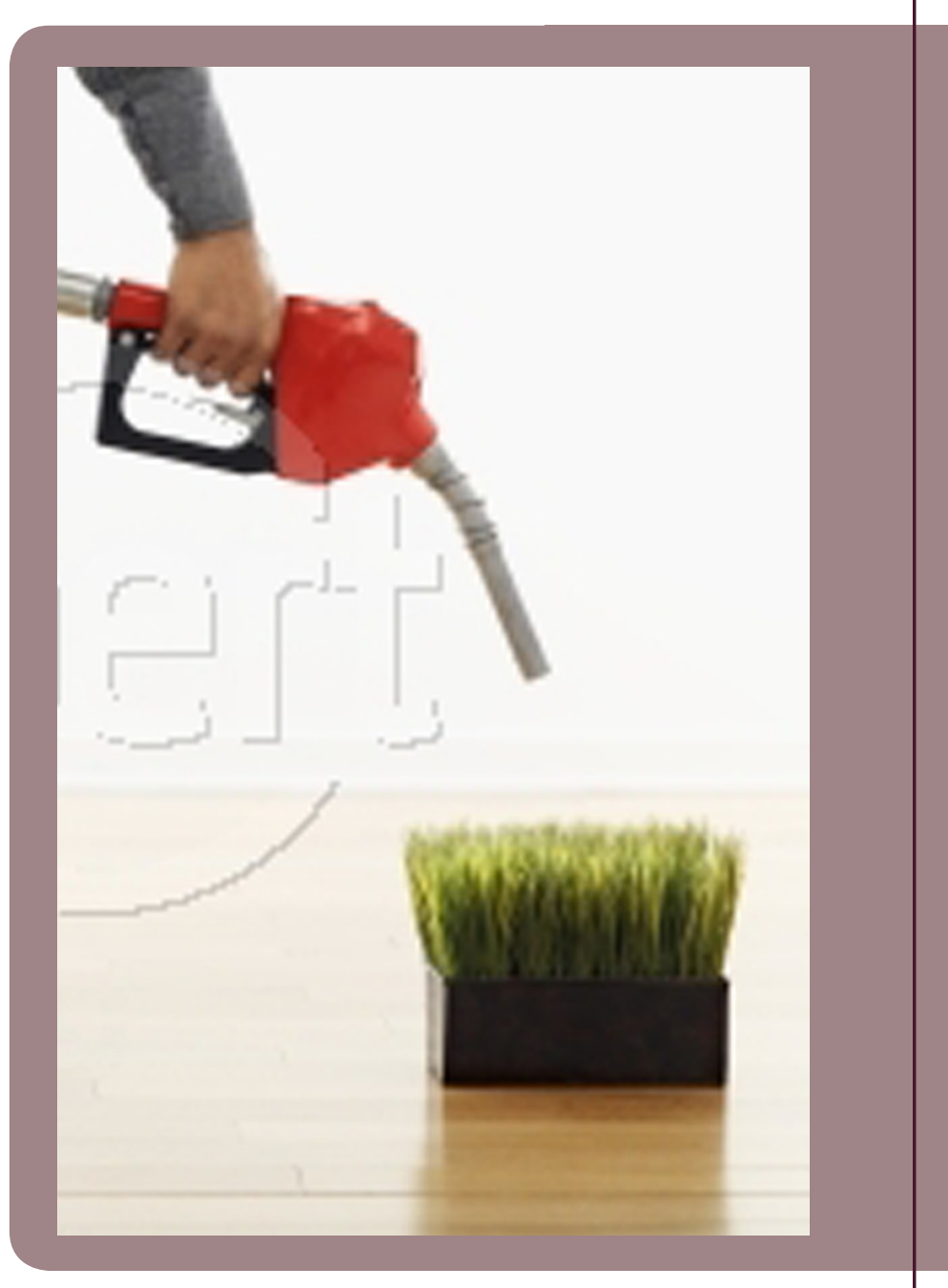

Kyoto.

- Mejorar la calidad del aire, reduciendo las emisiones que contribuyen al efecto invernadero (CO, CO2 , SO2).

- Reducir la importación de combustibles: Naftas de alto octano y diesel 2.

- Fomentar el desarrollo de la agroindustria, mediante el establecimiento de nuevos cultivos agrícolas para incrementar la producción de alcohol y aceites vegetales.

- Mejorar la calidad de los combustibles: Reducción de contenido de aromáticos, bencenos, olefinas y azufre.

- Diversificación de la agricultura en materias primas para la bioenergía.

- Desarrollo de infraestructura y empleo en áreas rurales.

- Diversificación de la oferta nacional de energía.

- Más tiempo para actividades generadores de ingresos rurales 
Para analizar algunas de las particularidades de la

Respaldado por el marco legal establecido, el estado ecuatoriano, se a propuesto implementar un programa de biocombustibles, en base al procesamiento de la caña de azúcar para producir etanol y de palma africana para la producción de biodiesel. En el contexto referido, se prevé la expansión de las áreas de estos cultivos, pues ya existen 85.000 hectáreas destinadas a la producción de azúcar y 55.000 has destinadas a la producción de panela y aguardiente, así como 207285 hectáreas plantadas con palma africana; pero también se comenta acerca de un proyecto que plantea establecer entre 50 000 a 100000 hectáreas de higuerilla (Ricinus comunis), piñón (Jatropha curcas) e inchi (Caryodendron orinocense Karst), que se ubicarían entre las provincias de Manabí y Esmeraldas, y hay quienes hablan también de implementar proyectos para la obtención de metanol a partir del maíz (Zea mays) o de soya (Glycine max L ) para la obtención de biodiesel.

De acuerdo con la información del III Censo Nacional Agropecuario (2000), el 47 \% de la superficie del país, es decir 12’355 831 hectáreas, se dedican a la producción agropecuaria.

El MAGAP (2007), estima que el área agrícola potencial en el país es de 6’333 000 hectáreas, de las cuales el área neta regable es de 3'100 000 hectáreas; con una superficie cultivada de 1'850 000 hectáreas y con una infraestructura de riego para apenas 955000 hectáreas, lo que significa que apenas está servida con riego el $30.8 \%$ de la área regable estimada. De esta área el $70 \%$ corresponde a riego privado y el $30 \%$ a riego público.

Ante esta situación, surgen varias interrogantes:

- ¿Cuál es la experiencia de los países que han incursionado en la producción de agrocombustibles?

- ¿Sobre que tierras se propone implementar los cultivos que se destinarán para la obtención de los biocombustibles, identificados más como agrocombustibles?

- ¿Se extenderá aún más la frontera agrícola, comprometiendo áreas boscosas, o se ocuparán áreas dedicadas a cultivos alimenticios?

- ¿Cuáles son las tecnologías que se aplicarán para el manejo de los agrocombustibles?

- ¿ Cuáles serían los impactos que se generarían por efecto de la implementación de cultivos para la obtención de agrocombustibles?

El propósito del presente trabajo, es dar satisfacción a las interrogantes arriba formuladas y determinar la pertinencia de los agrocombustibles para la sociedad ecuatoriana. Análisis de la Producción de Cultivos Destinados para la
Obtención de Agrocombustibles producción de los cultivos que se destinan a la obtención de los agrocombustibles, nos remitiremos al análisis de casos, poniendo énfasis en la realidad de países latinoamericanos, donde estas actividades ya se vienen ejecutando:

\section{El caso de la caña de azúcar en el Valle del Cauca-Colombia}

El modelo de producción tanto de azúcar como de agrocombustibles en el Valle del Cauca, se fundamenta en los postulados de la revolución verde: Concentración de la tierra, concentración de las fuentes de agua, uso indiscriminado de agrotóxicos de síntesis petroquímica, uso de organismos genéticamente modificados "OGMs", mecanización del suelo, contaminación del suelo, agua y aire. El paquete completo de revolución verde ha demostrado ser altamente perjudicial para el medio ambiente, en tanto que el 52\% de los gases de efecto invernadero son producidos por los agrotóxicos, utilizados en este tipo de agricultura.

El uso del suelo para monocultivos reduce significativamente la biodiversidad, destruye los procesos de sinergia y simbiosis del suelo potencializándose la aparición de plagas, cambia drásticamente los patrones microclimáticos y por tanto de humedad del suelo y de ciclaje de nutrientes.

La concentración de las fuentes de agua trae como consecuencia reducciones significativas de la capacidad de dilución de las sales minerales en las fuentes de agua de los humedales, lo que conlleva a su colmatación y putrefacción, matando a plantas y animales que en otros tiempos fueron consumidos por las comunidades, no obstante, el impacto ambiental más grave, es la reducción de los caudales de agua de consumo por las poblaciones ribereñas del Río Cauca.

En la actualidad se generan cerca de 1'100 000 litros/ día de etanol, que para ser producidos requieren entre 4-12 litros de agua por litro de Etanol, por tanto, si consideramos el requerimiento más bajo de agua (4 litros), producir etanol requiere 4400 m3/día. En la actualidad las 37000 hectáreas de caña sembradas para etanol se consumen 18'500 000 m3 de agua/año.

El uso indiscriminado de agrotóxicos ha salinizado el suelo, ha conllevado a que las propiedades físicas y químicas del suelo se atrofien, disminuyéndose la capacidad de las plantas de absorber los nutrientes del suelo, los agrotóxicos contaminan el agua subterránea, el aire arrastra trazas de agroquímicos por la acción del viento hacia zonas sembradas con cultivos diferentes a la caña, causándose pérdidas en los cultivos de los campesinos de las zonas medias de la cordillera central.

La mecanización ha provocado que el suelo se compacte, que se destruyan las propiedades físicas y químicas 
de uno de los valles más fértiles de Colombia, como es el Valle del Río Cauca.

Las quemas de caña generan altas cantidades de gases de efecto invernadero como CO2 y NOx, también producen material particulado que afecta la salud de humanos y animales en las zonas rurales y en los centros poblados.

Se a llegado ha establecer que los Agrocombustibles no solucionan el problema del calentamiento global, por el contrario lo agravan, ya que la combustión con mayor presencia de productos oxigenados aumenta las concentraciones de NOx, genera ozono y acetaldehídos, estos actúan como cancerígenos en humanos. Además se debe tener en cuenta que para producir etanol se requiere de combustibles fósiles.

De este modo, para que la producción de Etanol siga siendo "rentable" para los empresarios agroexportadores, la flexibilidad laboral, que trae consecuencias desastrosas para los trabajadores deberá acrecentarse y además para aumentar la producción de etanol, el proceso tendrá que ser mecanizado. Por tanto, existen dos panoramas que se interrelacionan de continuarse por el camino de los agrocombutibles, por un lado el aumento de la explotación laboral para los trabajadores de la agroindustria de los agrocombustibles y por el otro la sustitución de mano de obra por máquinas altamente dependientes de combustibles fósiles.

No obstante, estudios adelantados en Brasil demuestran que 100 hectáreas utilizadas en agricultura familiar generan 35 empleos directos, mientras que si éstas son utilizadas para la producción de agrocombustibles solo generan 10 empleos, por los tanto si las aproximadamente 300000 hectáreas que se propone sembrar con cultivos para "agrocombustibles" en el Ecuador, se destinarán a la agricultura familiar se podrían generar 105000 empleos, versus 30000 que se generarían si las tierras son usadas para la producción de agrocombustibles.

\section{El caso de la producción de soya}

En Argentina, el avance arrollador de la soya o soja y otros monocultivos dedicados a la agroindustria generaron una caída del número de productores rurales, con una disminución en especial de productores familiares, y conflictos con otros usos productivos que se redujeron o trasladaron (por ejemplo lechería, algodón, cereales, etc.), concentración de la tierra, proliferación de contratos donde los dueños de los predios ceden la gestión a empresas o inversores, e implantación de paquetes tecnológicos con transgénicos.

Estas condiciones explican en parte los bajos costos de producción en países como Brasil, ya que se logran por carencias dramáticas en la dimensión laboral, y que convierten a cultivos como la soja o la caña de azúcar en una estrategia insustentable en la perspectiva social de la sustentabilidad.

Por otra parte, no es seguro que los biocombustibles generen un aumento en la demanda de empleo rural. Si se analiza el caso de la soya en Brasil, uno de los potenciales cultivos para producción de biodiesel, el avance de su implantación ha ido de la mano de una disminución del empleo. En efecto, mientras que en 1985 se producían 18.278 toneladas de soya con 1'694 000 agricultores, en el 2004 se producen 49792 toneladas con apenas 335 mil trabajadores. Schlesinger 2006.

Al contrario de lo que afirman sus promotores, como Estados Unidos y la Unión Europea, que serían una respuesta ambientalmente amigable frente al cambio climático producido por los combustibles derivados del petróleo, esta nueva ola de monocultivos industriales no mitigarán ninguno de los problemas existentes y creará nuevos.

Según las condiciones y el cultivo, puede incluso dar saldo negativo. Si se incluyen en la ecuación la destrucción de ecosistemas como bosques y sabanas, o el hecho de que las refinerías de etanol y las plantas de procesamiento de celulosa son una fuente de contaminación del ambiente y la salud de los habitantes cercanos, el saldo definitivamente es negativo. Irónicamente, las industrias argumentan que los cultivos normales no rinden lo suficiente, e intentan justificar cultivos y árboles transgénicos - para producir etanol a partir de celulosa-, que agregarían otra gama de amenazas.

Las industrias y gobiernos del Norte necesitan que la producción sea en los países del Sur, en parte porque no disponen de tierra o no quieren usarla para esto, y porque asumen que en esos países los problemas ambientales son obviados por gobiernos ávidos de "inversión" extranjera y de promover la agricultura intensiva de exportación, en desmedro de sistemas locales integrales que constituyan su propia soberanía alimentaria. Las instituciones financieras internacionales (Banco Mundial, Banco Interamericano) ya anuncian que "apoyarán" esta conversión, metiendo en la trampa a pequeños y medianos productores y aumentando las deudas externas de los países.

Claramente hay un proyecto geopolítico de Estados Unidos para disminuir su dependencia de las naciones petroleras, pero además, un interés propio de las empresas que están detrás de esta nueva devastación agrícola: para las industrias que controlan los agrocombustibles (grandes distribuidores de cereales como Cargill, ADM y Bunge, productores de semillas transgénicas como Syngenta, DuPont, Monsanto, Bayer, Dow y las automotoras, todo son ganancias: reciben subsidios directos o indirectos, leyes a su favor y una significativa extensión de las tierras y agricultores dedicados a producir las materias primas que necesitan, al precio que definen, y cada vez más controlarán 
al aumentar la competencia entre países.

Los agro-combustibles constituyen así un proyecto de recolonización imperial, en un nuevo asalto de las industrias transnacionales a las economías campesinas y a la soberanía alimentaria.

\section{Las Posibles Áreas para Producción de Agrocombustibles}

A través de sus voceros, el estado ecuatoriano, ha venido en los últimos tiempos haciendo algunas consideraciones alrededor de la pertinencia de llevar adelante en el territorio nacional, la producción de cultivos destinados para la obtención de agrocombustibles.

Entre los argumentos que se esgrimen para tal propósito, se encuentran los siguientes:

- Las importaciones de combustibles significan un alto costo para el Estado.

- Existen iniciativas privadas para la instalación de plantas de obtención de biocombustibles.

- Hay expectativa de la ciudadanía y de los pequeños agricultores. - En el aspecto social se espera generación de empleo y desarrollo del sector rural.

- En el aspecto ambiental, se espera la reducción de emisiones.

- El Ministerio de Electricidad y Energía Renovable tiene como política, fomentar el uso de energía renovable y desarrollo de industria local con sistemas de energías limpias.

- Hay que diversificar la matriz energética, considerando una economía post-petrolera!!!

- Existen recursos agrícolas que permiten la producción de biocombustibles. (Condiciones climáticas y ubicación favorable)

Curiosamente, estos argumentos, son los mismos que de parte interesada se vienen pregonando en el tercer mundo (África, América) y que se orientan a satisfacer la demanda de los consumidores que quieren seguir manteniendo su estándar de vida basada en el derroche, pero que quieren tranquilizar su conciencia al poner en el tanque de su automóvil un $5.75 \%$ de biocombustible, que puede proceder de las destrozadas selvas brasileras, de las pampas argentinas, paraguayas o bolivianas, donde los campesinos han sido expulsados en la mayoría de los casos violentamente.

En muchos sectores del país, ya se viene promocionando con fuerza los cultivos que se dedicarán a la obtención de agrocombustibles y también ya se están ejecutando acciones.

En la provincia de Esmeraldas, la situación va viento en popa, pues hay la autorización expresa para echar abajo 50000 hectáreas de bosque primario, para reemplazarlas por cultivos de palma aceitera. La destrucción del bosque primario y su biodiversidad son evidentes, los cambios climáticos en el área de igual manera ya son notables, mientras que las comunidades negras y chachis, cada vez con más insistencia hacen sentir su inconformidad.

Según Rosero (2007), El proyecto para producir etanol, se propone sembrar en el país 50000 nuevas hectáreas con caña de azúcar, respondiendo a la siguiente estrategia: Esmeraldas (4 000 ha) Manabí (3 000 ha), Entre Bolívar y Los Ríos (5 000 ha), entre Cañar y Guayas (20 000 ha) en el Oro (4 000 ha), Imbabura (2 500 ha), en Azuay(2 500 ha) y en Loja (3 000 ha).

En el Noroccidente del Pichincha, concretamente en la localidad de Pedro Vicente Maldonado, un gran letrero colocado a las puertas de las Oficinas del MAGAP, invita a los agricultores a participar en el proyecto de caña (2 000 ha), para la obtención de biocombustibles. Se acabará con el último relicto de bosque húmedo tropical que le queda a la provincia del Pichincha, se acabará la producción agropecuaria diversificada, se pondrá el epitafio para el naciente negocio del agroecoturismo de la zona, sus hasta ahora fuentes de agua limpia, terminarán siendo contaminadas de manera irremediable.

La propuesta de la siembra de caña, propone plantaciones en las estribaciones de la cordillera oriental que da hacia la vertiente amazónica y en las estribaciones de la cordillera occidental, hacia la vertiente pacífica, donde indudablemente se procederá a la tumba de montaña, que por un lado es la protección de las cuencas hidrográficas más fértiles del mundo: El Valle del Río Portoviejo, la cuenca del Guayas y la cuenca del Jubones, mientras que por el otro es el origen de muchos de los afluentes que constituyen la gran Cuenca Amazónica, que representa para la humanidad una de las grandes reservas de biodiversidad y agua.

Es importante destacar que en cuanto a la disponibilidad de la tierra, se han generado análisis que presentan la superficie potencialmente utilizable por la agricultura, asumiendo que sobre ella se pueden implantar los nuevos cultivos para generar combustibles. Esta línea de razonamiento olvida elementos claves de la sustentabilidad.

En primer lugar, lo que tradicionalmente se define como superficie potencialmente utilizable por la agricultura (o arable) incluye enormes extensiones de áreas naturales.

El ejemplo más claro se observa en la ecoregión del Cerrado en Brasil, con una superficie aproximada de 200 millones de hectáreas, donde ya se encuentran en producción agrícola y ganadera unos 50 millones de hectáreas, y se ha postulado sumarle otros 75 millones de hectáreas. Esta es una reconversión de enorme escala y profundos impactos en la biodiversidad. Situaciones similares se viven en zonas amazónicas, no sólo en Brasil, sino también en Ecuador y Perú, a 
la luz de iniciativas de agrocombustibles en esos ecosistemas. En segundo lugar, la ampliación de las áreas agrícolas aumentará los problemas de alteraciones en los recursos hídricos, deterioro de los suelos e impactos de agroquímicos y otros contaminantes.

Se conoce que tanto Brasil, como Argentina, Paraguay y Bolivia, han presupuestado grandes extensiones de su territorio para la siembra y obtención de biocombustibles, frente a lo cual nuestro país con su escasa superficie destinada a la producción de cultivos para elaborar agrocombustibles, no tiene mayores expectativas en el concierto latinoamericano, como si lo tiene en cuanto a la producción de alimentos.

\section{Tecnologías que demandan los Cultivos destinados para la Elaboración de Agrocombustibles}

\section{Preparación del suelo y manejo del cultivo}

De manera invariable, todos los cultivos destinados para la elaboración de biocombustibles, se manejan como monocultivos y como tales demandan tecnologías que ponen énfasis en la mecanización agrícola, tanto para la preparación de los suelos, como para la cosecha, poscosecha y transporte de la producción hacia los centros de acopio y hacia las fábricas de biocombustibles, de igual manera requieren de altas cargas de agrotóxicos: Fertilizantes y plaguicidas (insecticidas, fungicidas, acaricidas, nematicidas y herbicidas).

Tanto la maquinaria agrícola, como los fertilizantes y plaguicidas, son altamente dependientes de los hidrocarburos, teniendo un alto poder contaminante.

Las semillas de cultivos como el maíz y la soya destinadas para la elaboración de agrocombustibles, son de naturaleza transgénica, cuyas patentes responden a los intereses de las transnacionales Syngenta, Monsanto, Dupont, Dow Chemical.

Por otra parte tanto la soya, como el maíz, son cultivos que se manejan en hileras, y que por lo tanto contribuyen a la erosión del suelo y a la contaminación del agua y requieren grandes cantidades de fertilizantes, plaguicidas y combustible para la plantación, cosecha y secado.

Constituyen la causa fundamental del derrame de nitrógeno -la peligrosa fuga de nitrógeno de los campos cuando llueve- del tipo que ha creado la llamada Zona de la Muerte en el Golfo de México, un área del océano del tamaño de Nueva Jersey que tiene tan poco oxígeno que apenas admite la vida.

En los Estados Unidos, el maíz y la soya se cosechan generalmente como cultivos de rotación porque la soya le agrega nitrógeno al suelo que el maíz necesita para crecer. Pero como el maíz desplaza cada vez más a la soya como fuente principal de etanol, se cultivará constantemente lo que a la vez requerirá aumentos sustanciales de fertilizantes nitrogenados y agravará el problema de la pérdida de nitrógeno.

Los cultivos destinados para la producción de agrocombustibles, al manejarse como "monocultivos" demandan de elevados niveles de fertilización, especialmente nitrógeno, elemento que por su causticidad es capaz de desactivar biológicamente los suelos, acidificarlos y contaminar los niveles freáticos por su alta movilidad, comprometiendo la absorción de nutrimentos por parte de las plantas y la salud de la gente que consume éstas aguas.

De la misma manera los monocultivos al romper el equilibrio biológico contribuyen para la aparición de una serie de plagas (insectos, ácaros, nemátodos y patógenos) que a su vez son controlados por una amplia gama de agrotóxicos (insecticidas, acaricidas, nematicidas, fungicidas, etc.).

El uso de semillas transgénicas de soya, viene aparejado al uso de Roundup (Glifosato), pues la semilla RR (Roundup Ready) es resistente a este agrotóxico, cuyo efecto en el suelo contribuye a desactivar la biología del suelo, con la consiguiente aparición de fitopatógenos como el Fusarium oxisporum, que produce el marchitamiento de todo tipo de cultivos.

A continuación, se muestran las tecnologías de manejo agroquímico de algunos de los cultivos destinados a la producción de agrocombustibles.

Manejo agroquímico de cultivos para la producción de agrocombustibles

Cultivo de Maíz (Zea mays)

\begin{tabular}{|l|l|}
\hline \multicolumn{1}{|c|}{ TECNOLOGÍA PARA: } & \multicolumn{1}{|c|}{ PRODUCTOS } \\
\hline Siembra: & Semilla transgénica: Var 3272 \\
\hline Fertilización & $\begin{array}{l}\text { Úrea, Fosfato de amonio, Muriato de } \\
\text { Potasio }\end{array}$ \\
\hline Control de plagas (insectos) & $\begin{array}{l}\text { Dipterex, Baytroide, Carbofurán, } \\
\text { Malathion }\end{array}$ \\
\hline Control de malezas & 2-4D, Roundup (Glifosato) \\
\hline
\end{tabular}

Cultivo de Soya (Glicine max)

\begin{tabular}{|l|l|}
\hline \multicolumn{1}{|c|}{ TECNOLOGÍA PARA: } & \multicolumn{1}{c|}{ PRODUCTOS } \\
\hline Siembra: & Semilla transgénica: RR (Roundup Ready) \\
\hline Fertilización & Fosfato de amonio, Muriato de Potasio \\
\hline Control de plagas (insectos) & $\begin{array}{l}\text { Lorsban. Cipermetrina, Omite, Nuvacron, } \\
\text { Clorpirifos, Vitavax, Polo, Palmarol, }\end{array}$ \\
\hline Control de malezas & 2-4D, Roundup (Glifosato) \\
\hline
\end{tabular}


Cultivo de Caña de Azúcar (Sacharun officinalis)

\begin{tabular}{|l|l|}
\hline \multicolumn{1}{|c|}{ TECNOLOGÍA PARA: } & \multicolumn{1}{|c|}{ PRODUCTOS } \\
\hline Siembra: & Semilla: Variedades mejoradas \\
\hline Fertilización & $\begin{array}{l}\text { Úrea, Nitrato de amonio, Muriato de } \\
\text { Potasio }\end{array}$ \\
\hline Control de plagas (insectos) & $\begin{array}{l}\text { Dipterex, Pirimicarb, Carbofurán, } \\
\text { Malathion, Evisect, Captan }\end{array}$ \\
\hline Control de malezas & Roundup (Glifosato), 2-4D, Gramoxone \\
\hline
\end{tabular}

Cultivo de Palma Aceitera (Eleais guinensis)

\begin{tabular}{|l|l|}
\hline \multicolumn{1}{|c|}{ TECNOLOGÍA PARA: } & \multicolumn{1}{|c|}{ PRODUCTOS } \\
\hline Siembra: & Semilla: Variedades mejoradas \\
\hline Fertilización & $\begin{array}{l}\text { Úrea, Nitrato de amonio, Muriato de } \\
\text { Potasio }\end{array}$ \\
\hline Control de plagas (insectos) & $\begin{array}{l}\text { Carbofuran, Captan, Endosulfan, Vitavax, } \\
\text { Triziman, Palmarol, }\end{array}$ \\
\hline Control de malezas & 2-4D, Roundup (Glifosato), Ranger \\
\hline
\end{tabular}

Cultivo de Piñón (Jatropha curcas)

\begin{tabular}{|l|l|}
\hline TECNOLOGÍA PARA: & \multicolumn{1}{|c|}{ PRODUCTOS } \\
\hline Siembra: & Semilla: Variedades mejoradas \\
\hline Fertilización & $\begin{array}{l}\text { Úrea, Nitrato de amonio, Muriato de } \\
\text { Potasio }\end{array}$ \\
\hline Control de plagas (insectos) & $\begin{array}{l}\text { Carbofuran,Endosulfan, Triziman, } \\
\text { Palmarol, Dithane M-45. }\end{array}$ \\
\hline Control de malezas & 2-4D, Roundup (Glifosato), Ranger \\
\hline
\end{tabular}

\section{Los Agrocombustibles y la Crisis Alimentaria}

\section{Los agrocombustibles y la producción de alimentos}

Un estudio interno del Banco Mundial que se filtró a la prensa responsabiliza a los biocombustibles por un 75\% del alza del precio de los alimentos que en los últimos años hizo caer a unas 100 millones de personas por debajo de la línea de pobreza.

Una de las discusiones principales sobre el modelo agrícola global gira en torno a la incidencia de la producción de agrocombustibles en la actual crisis mundial de alimentos.

Jean Ziegler, relator de la Organización de las Naciones Unidas para la Alimentación FAO, denunció que "para llenar el tanque de un automóvil que funcione con biocarburante, se requieren aproximadamente 200 kilos de maíz", que es el consumo de una persona al año. Por su parte, Lula dice que "los biocombustibles no son el villano que amenaza la seguridad alimentaria", arguyendo que sólo cubren el 0,9\% de la tierra.

En Colombia, el Ministerio de Agricultura, también, con argumentos similares a los del presidente brasilero, fijó la producción de agrocombustibles como una prioridad de su gestión. Prueba de ello es la decisión tomada frente al predio
Carimagua entregado a Ecopetrol para elaborar etanol, pasando sobre la destinación obligatoria que tenía para la población desplazada.

Decir que la abundancia de tierra disponible, valida la supremacía de los agrocombustibles sobre la comida, implica un desconocimiento de conceptos elementales de economía. Es sabido que cuando un país dedica mayores cantidades de recursos de producción a un determinado bien, debe reducir los que aplica a otros. Como la agricultura no necesita sólo tierra, sino también capital, mano de obra, tecnología y agua, la competencia entre dos productos del agro debe evaluarse considerando ese conjunto de requerimientos. Esto en Colombia es más necesario aún, teniendo en cuenta que casi todos estos factores son escasos, incluso la tierra, donde 10000 dueños poseen el 65\% del área total, algo similar a lo que ocurre en el Ecuador, donde la estructura agraria es un símbolo de inequidad, pues 636375 unidades productivas agropecuarias (UPAs), con (1'463 212 ha) de las 842882 UPAs existentes en el país, apenas ocupan el $12 \%$ del total de la superficie destinada a la producción agropecuaria (12’355 832 ha). Es la lección elemental de texto, la de la decisión entre fabricar cañones o mantequilla, entre elaborar mermelada u otra cosa.....

En los mercados mundiales, el maíz destinado a etanol en Estados Unidos, en 2000-2001 fue el 5\% de la cosecha total y para 2007-2008 el 25\%; gracias a lo cual los inventarios finales bajaron a la mitad y el precio en granja subió, de 2 dólares a 3.5 por bushell $(2.84 \mathrm{~kg})$.

El uso industrial de aceites vegetales en la Unión Europea tiene trazos comunes, pasó de demandar 2 millones de toneladas en el 2000 para agrodiesel a casi 9 millones en el 2007. Estos incrementos en la demanda para fines energéticos o por cualquier otra razón no encuentran respuesta inmediata en la oferta y han influido para que los inventarios mundiales de granos hayan pasado de cubrir 120 días de consumo mundial en 2000 a apenas 60 días en el 2008. Dichos desequilibrios, para los cuales contribuyen tanto la elaboración de biocombustibles como otros motivos, son aprovechados así mismo por los fondos financieros para especular en las bolsas de valores de bienes básicos y para generar el fenómeno alcista.

Se ha llegado a argumentar, que los productores que destinen sus tierras a la producción de cultivos para la elaboración de agrocombustibles, tendrán ingresos suficientes, para financiar la adquisición de alimentos, sin embargo, pensar que con esas condiciones la exportación de agrocombustibles puede financiar las importaciones de alimentos es una ficción. Es lógico deducir que ni los términos de intercambio serán favorables en el corto ni en el mediano plazo ni que el competido mercado mundial, con rivales como Brasil en alcohol, o como Malasia o Argentina en aceite, está esperando los agrocarburantes del resto de países latinoamericanos -más 
costosos que los de muchos otros orígenes- entre los ya de por sí muy costosos carburantes de origen vegetal.

\section{El conflicto con la producción de alimentos}

Uno de los puntos más discutidos es un posible conflicto entre los cultivos destinados a alimentos y los que se usarán para combustibles. Algunos analistas, varios políticos y muchas empresas han desestimado este hecho, señalando que América Latina cuenta con una disponibilidad de tierras para uso agrícola tan alta, que puede producir tanto alimentos como agrocombustibles. Esta postura minimiza un problema que es real, y que además ignora que conflictos de similares características ya ocurren en la actualidad.

En efecto, ya existe en varios países un conflicto entre alimentos destinados a la demanda interna, y alimentos para exportación. En América Latina se encuentran por lo menos cinco países que presentan altos niveles de subnutrición mientras que son importantes agroexportadores: Bolivia, Guatemala, Honduras, Nicaragua y Paraguay. Incluso en naciones de grandes potencialidades, como Argentina, existen distorsiones en el mercado interno de alimentos (por ejemplo, la sojización extrema ha desplazado la ganadería lechera y este país enfrenta restricciones en la disponibilidad de productos lácteos.

El proceso de fondo que está operando corresponde a la dinámica del mercado, donde los grupos sociales de bajo ingreso son los más vulnerables ya que no pueden pagar los crecientes precios de los alimentos. Este es uno de los factores que explica que en América Latina logre muy modestas reducciones en los niveles de subnutrición (del 13\% en 199092 a 10\% en 2001-03, según datos de FAO, 2006), a pesar del continuo aumento de la producción agropecuaria.

Los agrocombustibles tienen todos los atributos para acentuar estos conflictos, ya que pueden tener niveles de rentabilidad mayores que los obtenidos con los alimentos, y en especial cuando son exportados.

Todas las estimaciones predicen un aumento de los precios futuros de los cultivos usados como combustibles; las diferencias sólo radican en el nivel de esos incrementos, por lo tanto, el conflicto entre alimentos y agrocombustibles ya está en marcha.

Si se reconocen esas tensiones, queda en evidencia que el problema de fondo se debe a la lógica económica que ha invadido la agricultura. Bajo esa perspectiva las decisiones productivas dependen de la rentabilidad económica, y como los destinos exportadores aseguran ganancias mayores, terminan siendo la fuerza motriz principal en estructurar al sector.
En síntesis, la fabricación de agrocombustibles sí compite con la producción de alimentos, les quita recursos productivos y, por esto, así como por la destinación de cereales y oleaginosos para la elaboración del combustible final, reduce los inventarios, contribuye al alza de los precios y refuerza la especulación financiera con la comida, crimen que hoy azota cruelmente a naciones enteras. Así, tan sencillo como grave.

\section{Conclusiones}

Del análisis hasta aquí realizado, se llega a las siguientes conclusiones:

- Que duro es comprobar que muchos productores, gobiernos y ciudadanos no saben que los suelos son fabricados por los bosques y ambientes nativos, y nunca por los cultivos industriales.

- Que duro es saber que para fabricar $2.5 \mathrm{~cm}$ de suelo en ambientes templados hacen falta de 700 a 1200 años y que los cultivos destinados para agrocombustibles los romperán en poquísimo tiempo.

- Que duro es recordar que buena parte de los bosques nativos y humedales de este país ya han sido destrozados y que funcionarios y productores no ven o no quieren ver que la única forma de tener un país más sustentable es conservar al mismo tiempo superficies equivalentes de ambientes naturales y de cultivos diversificados.

- Que duro es observar como se extingue el campesino que convivía con el monte, y como lo reemplaza una gran empresa agrícola que empieza irónicamente sus actividades destruyendo ese monte.

- Que duro es saber que las dosis de fertilizantes sintéticos y de glifosato, endosulfan, 2-4D y otros plaguicidas que se usarán masivamente en los cultivos para agrocombustibles pueden alterar el sistema hormonal de bebés, niños, adolescentes y adultos, y que no sabemos cuantos de ellos enfermarán y morirán.

- Que duro es saber que los bosques y ambientes nativos se desmoronan, que las cuencas hídricas donde se fabrica el agua van a ser en breve invadidas por cultivos para la elaboración de agrocombustibles...y que en nuestro país signado por la providencia para producir alimentos...éstos empiecen a faltar. - Que duro es ver las inmensas colas de desesperanzados en las puertas de las embajadas en pos de una visa para irse y muchas veces sin retorno.

\section{Recomendaciones}

Las recomendaciones, que se formulen, frente a esta realidad, deberán salir del concenso de los ciudadanos y ciudadanas que hacemos este hermoso y megadiverso país, poniendo a manera de orientación los siguientes puntos de vista, para llevar a la práctica el concepto del Sumak Alli Kausay (Buen Vivir), a fin de asegurar de esta manera a los seres humanos su reproducción y permanencia armoniosa con el cosmos: 
- Que el uso del suelo debe ser fundamentalmente para la producción de alimentos sanos.

- Que el estado debe establecer una política de investigación científica que revalide los aspectos más relevantes de nuestras tecnologías ancestrales a lo que se sumarán los más recientes avances de la ciencia y la tecnología (Agroecologia, Microbiología, Biotecnología), a fin de generar tecnologías acordes a nuestra realidad ecológica, económica y sociocultural.

- Que el estado debe invertir recursos para la producción agroecológica de alimentos que disminuya la dependencia a insumos derivados del petróleo y los agroquímicos.

- Que se establezca una política de créditos blandos para que las comunidades campesinas, indígenas y negras, puedan mantener y desarrollar sus actividades agropecuarias basadas en el modelo de economía campesina.

- El estado debe invertir recursos económicos para el establecimiento de agroempresas rurales para la transformación agroindustrial.

- El Gobierno Nacional, como los Gobiernos provinciales y municipales, conjuntamente con sus instituciones deben reconocer a las comunidades campesinas, indígenas y negras como sujetos de derechos sociales, políticos, culturales y ambientales, así como la autonomía en las decisiones sobre su territorio.

- Se deben crear mesas de trabajo para el análisis de la problemática de los habitantes del sector rural, que tiendan a la solución concertada de la problemática del campo.

- La inversión extranjera orientada fundamentalmente a la producción de alimentos, debe realizarse en condiciones ventajosas para el país y para las comunidades asentadas en los territorios en los que se realice la inversión.

\section{Bibliografía}

- Bravo, E. 2005. Soya-Instrumento de control de la agricultura y la alimentación. Acción Ecológica. Quito, EC. 167 p.

• 2008. Biocombustibles, cultivos energéticos y soberanía alimentaria. Acción Ecológica. Quito, EC. 151 p.

- Coordinación Campesina del Valle del Cauca..2008. Agrocombustibles la tragedia del campesinado. Ponencia de la Coordinación Campesina del Valle del Cauca en Pradera, Valle del Cauca. Consultado 29 de septiembre 2008. Disponible en http://www.indymedia.org/

- FAO. (2008). Agrocombustibles en el ojo de la tormenta por escalada de precios de alimentos a nivel mundial. (en línea). Consultado 29 de septiembre 2008. Disponible en www. radiomundoreal.fm/rmr/?q=taxonomy/term/6-

- Ibáñez, J. Tierras Marginales y Biocombustibles de Segunda Generación: Otra Gran Mentira (en línea). Foro para la soberanía alimentaria. Consultado 29 de septiembre 2008. Disponible en http// eblogs.madrinasd.org/universo/ archive/2008/06/04/93758.aspx

- Montenegro, R. 2008. Nos queremos suicidar o nos quieren matar (correo electrónico) Buenos Aires, AR
-Ribeiro, S. Agrocombustibles versus soberanía alimentaria. 2007. (en línea). Foro para la soberanía alimentaria. Consultado 29 de septiembre 2008. Disponible en http://alainet.orgnyéleni.

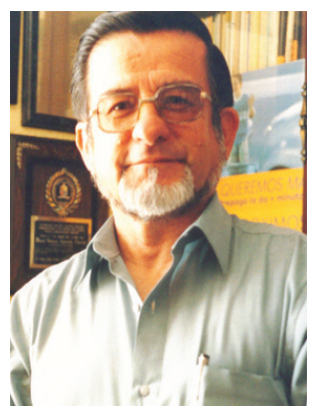

Autor: Manuel B. Suquilanda Valdivieso

El campo de mayor interés profesional del Ing. Suquilanda, es la producción orgánica de cultivos y el manejo sostenible de los sistemas productivos agropecuarios.

Por su trabajo en beneficio del ambiente y la producción limpia se hizo acreedor al Premio Nacional Planeta Azul -al mérito ecológico- y a la Condecoración Pío Jaramillo Alvarado -al mérito científico.

Actualmente ejerce la docencia en algunas universidades del país: Universidad Central del Ecuador, ESPOL, FLACSO, ESPE, UTE, Universidades de Guayaquil, Cuenca, Ambato, etc. Además se desempeña como asesor de empresas de producción bananera, cacaotera, hortícola y florícola, tanto en el país como en el extranjero. 